\title{
Comorbidity of Depression and Anxiety Leads to A Poor Prognosis Following Angina Pectoris Patients: A Prospective Study
}

Bingqing Bai

Guangdong Cardiovascular Institute囚 Guangdong Provincial People's Hospital, Guangdong Academy of Medical Sciences

Han Yin

School of Medicine, South China University of Technology \Guangzhou

Lan Guo

Department of Cardiac Rehabilitation, Guangdong Cardiovascular Institute, Guangdong Provincial People's Hospital, Guangdong Academy of Medical Sciences

Huan Ma

Department of Cardiac Rehabilitation, Guangdong Cardiovascular Institute, Guangdong Provincial People's Hospital, Guangdong Academy of Medical Sciences

Haochen Wang

School of Medicine, South China University of Technology $₫$ Guangzhou

Fengyao Liu

School of Medicine, South China University of Technology $₫$ Guangzhou

Yanting Liang

Guangdong Cardiovascular Institute区 Guangdong Provincial People's Hospital, Guangdong Academy of Medical Sciences

Anbang Liu

School of Medicine, South China University of Technology $₫$ Guangzhou

Qingshan Geng ( $\square$ gengqingshan@gdph.org.cn )

Guangdong Provincial People's Hospital, Guangdong Academy of Medical Sciences, Guangdong Cardiovascular Institute

\section{Research Article}

Keywords: Depression, anxiety, comorbidity, angina pectoris, prognosis, cardiovascular disease.

Posted Date: December 7th, 2020

DOI: https://doi.org/10.21203/rs.3.rs-112803/v1

License: (c) (1) This work is licensed under a Creative Commons Attribution 4.0 International License. Read Full License

Version of Record: A version of this preprint was published at BMC Psychiatry on April 20th, 2021. See the published version at https://doi.org/10.1186/s12888-021-03202-5. 


\section{Abstract}

Background: Depression and anxiety are two common psychiatric problems in patients with cardiovascular disease (CVD) and are associated with poor cardiac prognosis. The comorbidity of depression and anxiety is considered to be a more severe psychological status than non-comorbid psychiatric disorders. However, little is known about the relationship between depression or anxiety and noncardiac readmission. We conducted a prospective study on the prognostic impact of depression, anxiety, and comorbidity in angina pectoris (AP) patients.

Method: In this prospective study, 443 patients with AP were included in the analysis. Follow-up assessments were performed 1 year, and 2 years after patient discharges. Clinical outcomes of interest included readmission, major cardiovascular event (MACE), and composite events. Depression and anxiety symptom scores derived from the patient health questionnaire-9 (PHQ-9) and generalised anxiety disorder-7 (GAD-7) questionnaire were used to assess mood symptoms. Participants with symptom scores of $\geq 10$ on both questionnaires formed the comorbidity group. Using multivariable Cox proportional hazards models to evaluate the impact of psychiatric symptoms on clinical outcomes.

Results: Among all the AP patients, 271 (61.2\%) had non-depression symptoms and 172 (38. 9\%) were determined to have depression symptoms. As for anxiety symptoms, 316 (71.3\%), and 127 (28.7\%) patients had non-anxiety, and anxiety respectively. After controlling covariates, we found that patients who endured clinical depression (hazard ratio $[\mathrm{HR}]=2.12,95 \%$ confidence interval $[\mathrm{Cl}] 1.04-4.31, \mathrm{p}=0.038$ ) and anxiety $([\mathrm{HR}] 2.65,95 \%[\mathrm{Cl}] 1.12-6.30$, $\mathrm{p}=0.027$ ) had a high risk of noncardiac readmission. Compared to participants with no psychiatric symptoms, those with comorbidities of depression and anxiety presented a greater risk of MACEs $([\mathrm{HR}] 2.38,95 \%[\mathrm{Cl}] 1.11-5.10, \mathrm{p}=0.025)$ and noncardiac readmission $([\mathrm{HR}] 2.91,95 \%[\mathrm{Cl}] 1.03-8.18, \mathrm{p}=0.043)$ while the single-symptom group did not show any significances on all the events.

Conclusion: Depression and anxiety had predictive value for noncardiac readmission among patients with AP. Furthermore, prognoses were found to be worse for patients with comorbidities of depression and anxiety than those with single psychiatric symptoms. Additional attention needs to be focused on the initial identification and long-term monitoring of psychiatric comorbidity.

\section{Background}

Depression and anxiety have been linked to increased risk of coronary heart disease (CHD) and poor prognoses among patients with established cardiovascular disease[1-7]. Although the traditional risk factors for the development and prognosis of CHD are well known, psychosocial factors, especially depression and anxiety, are increasingly recognised[8]. A majority of studies have shown that depression is associated with a twofold to threefold increase in mortality or the risk of nonfatal cardiac events among patients with diagnosed CHD[9-11]. Anxiety is also an important predictor of recurring CV events among patients diagnosed with myocardial infarction or unstable AP[12-14]. With recurring CV events, the incidence of readmission also rises, which increases the cost of medical care and morbidity rates and affects the quality of life of patients[15]. Although the authors of many related studies paid attention to CVD, such as myocardial infarction or heart failure, and mainly focused on mortality or cardiac-related prognosis[16], there is a paucity of depression and anxiety research concentrated on the population of AP and noncardiac recurrent events.

Depression and anxiety often cooccur. Some studies have shown that there is a high degree of comorbidity between depression and anxiety[17-19], and this comorbidity may increase the risk of all-cause mortality, which leads to reductions in functional status compared to those of patients with only one of these disorders. It has also been suggested that patients with both depression and anxiety are at an increased risk of CVD[20]. However, few researchers have studied the population with both depression and anxiety and the association of this comorbidity with noncardiac readmission and MACEs.

We conducted a prospective cohort study to measure the prognostic impact of depression and anxiety on 443 AP patients. Our purpose was to examine the relationships between depression, anxiety, comorbidity, and noncardiac readmission in AP patients. We also analysed whether minor and major depression or anxiety symptoms, as assessed on a self-reported scale, can be used to predict the occurrence of CV events and readmission during a 29 months follow-up period after hospitalisation for AP.

\section{Material And Methods Study Design and Sample}

This is a prospective study in which we investigated the association between depression, anxiety, comorbidity, and the occurrence of hospital readmission and recurrent CV events during a 29-month follow-up period among AP patients. Patients were admitted to Guangdong Provincial People's Hospital from October 2017 to January 2018 for a cross-sectional study and were followed up with every six months to observe their prognosis after discharges. Professional cardiologists in the hospital persistently incorporated 705 patients with suspected CHD into the study. All patients underwent examinations and therapies considered to be the most appropriate by the attending cardiologist. A total of 705 copies of the questionnaire were issued, and all the completed copies were retrieved. A well-trained psycho-cardiologist explained the psychiatric scale to each patient one day before the coronary angiography and assisted those with impaired vision or poor reading ability to understand the contents of the scale. The study was approved by the Medical Ethics Committee of Guangdong Provincial People's Hospital. Written informed consent was obtained from all participants. Details about our recruitment strategy and excluded patients have been described in our previous article[21]. A total of 443 individuals with AP (according to the Braunwald standard) and diagnosed CHD were included for analysis.

\section{Follow-up}


Follow-up assessments were performed by telephone at 1 year, and over 2 years after discharges. The average follow-up time was $26.33 \pm 0.93$ months. Endpoint events included all-causes mortality, readmission, nonfatal stroke, MACE, and readmission included cardiac and noncardiac readmissions. Moreover, the composite endpoint covered all the above events, as well as revascularisation and the recurrence of nonfatal myocardial infarction. MACE included death, nonfatal stroke, cardiac readmission, revascularisation, and recurrence of nonfatal myocardial infarction. Due to the insufficient samples of death, nonfatal stroke, revascularisation, and recurrence of nonfatal myocardial infarction, we did not analyse these clinical events.

\section{Depression And Anxiety Measures}

Patient health questionnaire-9 (PHQ-9) and generalised anxiety disorder-7 (GAD-7) scales were used to assess depression and anxiety, respectively. We thoroughly elaborated on the utility of these scales in our previous article[21]. In our main analysis, a score of 5 or more was used as the depression symptom threshold because even mild depression symptoms, as classified by PHQ-9, are associated with relatively worse prognoses among cardiac patients[22]. We also used a cut-off score of 10 or more for the detection of clinical depression, and this diagnostic criteria has been shown to have $89 \%$ sensitivity and $89 \%$ specificity[23]. According to the wide use of the cut-off value of 5 , we compared the differences between patients with GAD-7 scores of $<5$ and $\geq 5$. Moreover, a GAD-7 score of $\geq 10$ indicated that the patient has clinical anxiety, in which the sensitivity and specificity for generalised anxiety disorder attained $89 \%$ and $82 \%$, respectively $[24,25]$. The Chinese version of PHQ-9 and GAD-7 has been validated in Chinese cardiac patients.[26, 27]

\section{Statistical Analysis}

We compared the characteristics of patients with different depression and anxiety symptoms. The normality test was performed on continuous variables. Clinical characteristics were compared between patients with questionnaire scores of $<5,5-9$, and $\geq 10$ with student's t-tests and Wilcoxon rank-sum tests for continuous variables and Chi-square or Fisher's exact test for categorical variables.

The survival analysis of depression and anxiety and baseline data was calculated using the Kaplan-Meier survival curve and the Log-Rank test. For statistically- or clinically-significant variables, the Cox proportional hazard regression model was used to adjust risk factors, including age, gender, education level, and severity of coronary artery stenosis. The specific classifications of covariates are illustrated in our previous article[21]. The interaction among all the covariates was considered. The HRs and $95 \% \mathrm{Cls}$ of the endpoint events of the enrolled patients were calculated based on nonpsychiatric, mild psychiatric, and moderate to severe psychiatric symptom groups. A P value of $<0.05$ indicates that the difference is statistically significant.

\section{Results}

\section{Prevalence and Correlates of Depression and Anxiety}

A total of 443 patients were enrolled in the study and assessed using PHQ-9 and GAD-7 scales. The baseline characteristics of the participants are shown in Table 1. The average participant was 63.9 years old ( \pm 9.8 years), and there were $337(76.1 \%)$ males and 106 females (23.9\%). Among all the AP patients, there were 271 (61.2\%) with no depression symptoms (PHQ-9 scores of $<5$ ) and $172(38.9 \%)$ with depression symptom (PHQ-9 scores of $\geq 5$ ), of which 49 (11.1\%) had clinical depression (PHQ-9 scores of $\geq 10$ ). As for anxiety symptoms, 103 (23.3\%), 13 (2.9\%), and 11 (2.5\%) patients had mild, moderate, and severe anxiety symptoms. The correlates of depression and anxiety were shown in our previous article[21]. 
Table 1

Baseline characteristic of depression, anxiety and comorbidity in AP patients.

\begin{tabular}{|c|c|c|c|c|c|c|c|c|}
\hline \multirow[t]{3}{*}{ Variates } & \multirow[t]{3}{*}{ Total } & \multirow{3}{*}{ 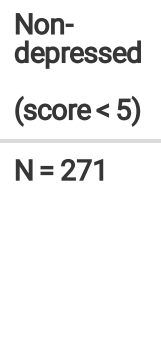 } & \multicolumn{2}{|l|}{$\begin{array}{l}\text { Depressed } \\
(\mathrm{N}=172)\end{array}$} & \multirow{3}{*}{$\begin{array}{l}\text { Non- } \\
\text { anxious } \\
(\text { score < 5) } \\
N=316\end{array}$} & \multicolumn{2}{|c|}{ Anxious(N = 127) } & \multirow{3}{*}{$\begin{array}{l}\begin{array}{l}\text { Clinical } \\
\text { Comorbidity }\end{array} \\
(\mathrm{N}=19)\end{array}$} \\
\hline & & & $\begin{array}{l}\text { mild dep. } \\
(5 \leq \text { score < } \\
10)\end{array}$ & $\begin{array}{l}\text { mod-severe } \\
\text { dep. } \\
(\text { score } \geq 10)\end{array}$ & & $\begin{array}{l}\text { mild anx. } \\
(5 \leq \text { score }< \\
10)\end{array}$ & $\begin{array}{l}\text { mod-severe } \\
\text { anx. } \\
\text { (score } \geq 10 \text { ) }\end{array}$ & \\
\hline & & & $N=123$ & $N=49$ & & $N=103$ & $N=24$ & \\
\hline Age,mean $\pm S D, y$ & $63.9 \pm 9.8$ & $63.0 \pm 9.5$ & $65.5 \pm 10.0$ & $64.9 \pm 10.8$ & $64.2 \pm 9.9$ & $63.4 \pm 8.9$ & $\begin{array}{l}62.5 \pm \\
12.7\end{array}$ & $64 \pm 9.8$ \\
\hline Male,No.(\%) & $337(76.1)$ & 223(82.3) & $79(64.2)$ & $35(71.4)$ & 256(81.0) & $63(61.2)$ & 18(75.0) & 14(73.7) \\
\hline \multicolumn{9}{|l|}{ Marriage,No.(\%) } \\
\hline Married & 412(93.0) & 258(95.2) & 112(91.1) & $42(85.7)$ & 294(93.0) & 96(93.2) & 22(91.7) & 17(89.5) \\
\hline $\begin{array}{l}\text { Divorced or } \\
\text { Widowed } \\
\text { or Single }\end{array}$ & $31(1.6)$ & $13(4.8)$ & $11(8.9)$ & $7(14.3)$ & $22(7.0)$ & $7(6.8)$ & $2(8.3)$ & $2(10.5)$ \\
\hline \multicolumn{9}{|l|}{$\begin{array}{l}\text { Severity of } \\
\text { coronary } \\
\text { stenosis,No.(\%) }\end{array}$} \\
\hline 1 & $93(21.0)$ & $51(18.8)$ & $33(26.8)$ & $9(18.4)$ & $56(17.7)$ & $32(31.1)$ & $5(20.8)$ & $4(21.1)$ \\
\hline 2 & $82(18.5)$ & $54(19.9)$ & 19(15.4) & $9(18.4)$ & $64(20.3)$ & 11(10.7) & $7(29.2)$ & $5(26.3)$ \\
\hline 3 & $268(60.5)$ & $166(61.3)$ & 71(57.7) & $31(63.3)$ & $196(62.0)$ & $60(58.3)$ & $12(50.0)$ & $10(52.6)$ \\
\hline
\end{tabular}

\section{Follow-up Events}

All 443 patients received follow-up calls for readmissions, MACEs, and composite endpoints. The censored data contained loss to follow-up and endpoint events that had not occurred at the end of the study. There were 88 MACEs and 129 composite endpoints during the 29-month follow-up period. In this study, there were 74 cardiac readmissions and 46 noncardiac readmissions(Figure 1). The incidence of follow-up events in different groups is shown in Table 2.

Table 2

The incidence of follow-up events in depression, anxiety and comorbidity groups.

\begin{tabular}{|c|c|c|c|c|c|c|c|c|}
\hline \multirow[t]{3}{*}{ Event } & \multirow[t]{3}{*}{$\begin{array}{l}\text { No. } \\
(\%)\end{array}$} & \multirow{3}{*}{$\begin{array}{l}\begin{array}{l}\text { Non- } \\
\text { depressed }\end{array} \\
\text { (score< 5) } \\
\mathrm{N}=271\end{array}$} & \multicolumn{2}{|l|}{$\begin{array}{l}\text { Depressed } \\
(\mathrm{N}=172)\end{array}$} & \multirow{3}{*}{$\begin{array}{l}\text { Non- } \\
\text { anxious } \\
(\text { score }<5) \\
N=216\end{array}$} & \multicolumn{2}{|c|}{ Anxious $(\mathrm{N}=127)$} & \multirow[t]{3}{*}{$\begin{array}{l}\text { Clinical } \\
\text { Comorbidity* } \\
\mathrm{N}=19\end{array}$} \\
\hline & & & $\begin{array}{l}\text { mild dep. } \\
(5 \leq \text { score < } \\
10)\end{array}$ & $\begin{array}{l}\text { mod-severe } \\
\text { dep. } \\
(\text { score } \geq 10)\end{array}$ & & $\begin{array}{l}\text { mild anx. } \\
(5 \leq \text { score < } \\
10)\end{array}$ & $\begin{array}{l}\text { mod-severe } \\
\text { anx. } \\
\text { (score } \geq 10)\end{array}$ & \\
\hline & & & $N=123$ & $N=49$ & & $N=103$ & $N=24$ & \\
\hline Cardiac & 74 & $44(59.5)$ & $21(28.4)$ & $9(12.2)$ & $54(73.0)$ & $15(20.3)$ & $5(6.8)$ & $4(21.0)$ \\
\hline noncardiac & 46 & 19(41.3) & 17(37.0) & $10(21.7)$ & $32(70.0)$ & $8(17.4)$ & $6(13.0)$ & $5(10.9)$ \\
\hline Mace & 88 & $49(18.1)$ & $25(20.3)$ & $14(28.6)$ & 61(69.3) & 18(20.5) & $9(10.2)$ & $8(9.1)$ \\
\hline Composite & 129 & $69(25.5)$ & 39(31.7) & 21(42.9) & $91(70.5)$ & 24(18.6) & 14(10.9) & $12(9.3)$ \\
\hline
\end{tabular}

Unadjusted HRs were estimated from a Cox proportional regression model for patients with nonpsychiatric, mild psychiatric, and moderate to severe psychiatric symptoms. Between the nondepressed and depressed group (see Additional file 1: Table S1), a significant difference of depression symptoms 
([HR] 2.35, 95\% [Cl] 1.31-4.23, p = 0.004) and the composite event ([HR] 1.43, 95\% [Cl] 1.01-2.02, $\mathrm{p}=0.043)$ were observed. But depressed symptoms were found to be not significantly associated with more cardiac readmissions ([HR] 1.08, 95\% [Cl] 0.68-1.2, $p=0.739)$ or MACEs ([HR] 1.91, 95\% [Cl] 0.41-3.43, $p=0.746)$. The prevalence of noncardiac readmission was associated with the occurrence of clinical depression $(\mathrm{HR}] 2.32,95 \%[\mathrm{Cl}] 1.15-4.68, \mathrm{p}=0.016)$ and the composite event ( $[\mathrm{HR}] 1.43,95 \%$ [Cl] 1.01-2.02, $\mathrm{p}=0.043$ ) (Table 3). Compared to the nonclinical depressive group, the clinical depressive group (i.e., those with PHQ-9 scores of $\geq 10$ ) were found to be at greater risk of noncardiac readmission ([HR] 2.32, 95\% [Cl] 1.15-4.68, p = 0.018). We did not observe a significant relationship between anxiety symptoms (GAD-7 scale $\geq 5$ ) and prognosis. However, clinical anxiety symptoms (as indicated by GAD7 scores of $\geq 10$ ) were found to have a strong significance with noncardiac readmission $([\mathrm{HR}] 2.71,95 \%[\mathrm{CI}] 1.15-6.40, \mathrm{p}=0.023)$ and the composite endpoint event $([\mathrm{HR}] 2.15,95 \%[\mathrm{Cl}] 1.23-3.74, \mathrm{p}=0.007)$ while MACE was found to be borderline significant in this group $([\mathrm{HR}] 1.98,95 \%[\mathrm{Cl}] 0.99-3.94, \mathrm{p}=$ 0.053).

Table 3

Results for clinical depression and clinical anxiety as predictors of follow-up events.

\begin{tabular}{|c|c|c|c|c|c|c|c|c|c|c|c|c|}
\hline \multirow[t]{2}{*}{ Event } & \multicolumn{6}{|c|}{ Clinical dep. vs not clinical dep. } & \multicolumn{6}{|c|}{ Clinical anx. vs not clinical anx. } \\
\hline & $\begin{array}{l}\text { Unadjusted } \\
\text { HR }\end{array}$ & $95 \% \mathrm{Cl}$ & $\mathbf{P}$ & $\begin{array}{l}\text { Adjusted } \\
\text { HR }\end{array}$ & $95 \% \mathrm{Cl}$ & $\mathbf{P}$ & $\begin{array}{l}\text { Unadjusted } \\
\text { HR }\end{array}$ & $95 \% \mathrm{Cl}$ & $\mathbf{P}$ & $\begin{array}{l}\text { Adjusted } \\
\mathrm{HR}\end{array}$ & $95 \% \mathrm{Cl}$ & $\mathbf{P}$ \\
\hline Noncardiac & 2.32 & $\begin{array}{l}1.15- \\
4.68\end{array}$ & $0.018^{*}$ & 2.12 & $\begin{array}{l}1.04- \\
4.31\end{array}$ & $0.038 *$ & 2.714 & $\begin{array}{l}1.15- \\
6.40\end{array}$ & $0.023^{*}$ & 2.65 & $\begin{array}{l}1.12- \\
6.30\end{array}$ & $0.027 *$ \\
\hline Cardiac & 1.09 & $\begin{array}{l}0.54- \\
2.19\end{array}$ & 0.810 & 1.22 & $\begin{array}{l}0.61- \\
2.46\end{array}$ & 0.569 & 1.259 & $\begin{array}{l}0.51- \\
3.12\end{array}$ & 0.619 & 1.26 & $\begin{array}{l}0.51- \\
3.13\end{array}$ & 0.621 \\
\hline Mace & 1.52 & $\begin{array}{l}0.86- \\
2.70\end{array}$ & 0.569 & 1.62 & $\begin{array}{l}0.91- \\
2.88\end{array}$ & 0.099 & 1.978 & $\begin{array}{l}0.99- \\
3.94\end{array}$ & 0.053 & 2.02 & $\begin{array}{l}1.01- \\
4.05\end{array}$ & $0.046^{*}$ \\
\hline Composite & 1.59 & $\begin{array}{l}0.997- \\
2.54\end{array}$ & 0.052 & 1.60 & $\begin{array}{l}1.001- \\
2.57\end{array}$ & $0.049 *$ & 2.146 & $\begin{array}{l}1.23- \\
3.74\end{array}$ & $0.007^{\star}$ & 2.20 & $\begin{array}{l}1.26- \\
3.84\end{array}$ & $0.006^{*}$ \\
\hline \multicolumn{13}{|l|}{$*: P<0.05$} \\
\hline Abbreviatior & p.: depressi & ; anx.: a & ious & & & & & & & & & \\
\hline
\end{tabular}

The multivariable-adjusted analysis of depression and anxiety included four factors, age, gender, education, and severity of coronary artery stenosis. Compared to patients without depression symptoms, patients with depression symptoms (as indicated by PHQ-9 scores of $\geq 5$ ) remained at higher risk for noncardiac readmission ([HR] 1.98, 95\% [Cl] 1.08-3.63, $\mathrm{p}=0.03$ ) (see Additional file 1: Table S1). Participants with clinical depression ([HR] 2.12, 95\% [Cl] $1.04-4.31, p=0.038)$ and clinical anxiety $([\mathrm{HR}] 2.65,95 \%[\mathrm{Cl}] 1.12-6.30, \mathrm{p}=0.027)$ were found to be at greater risk of noncardiac readmission than others, even after adjustment. Moreover, clinical anxiety participants reported significantly more MACEs ([HR] 2.02, 95\% [Cl] 1.01-4.05, $p=0.046)$ than nonclinical anxiety participants after adjustment (Table 3). In addition to depression and clinical anxiety, old age was identified as a risk factor for noncardiac readmission events. No statistical significance was shown between depression or anxiety and cardiac readmission events.

Furthermore, we divided participants with psychiatric disorders into three groups: those with no mental disorders, those with only one mental disorder, and those with both depression and anxiety. The unadjusted analysis (Table 4) showed that comorbidity had great significance in increasing noncardiac readmission ([HR] 3.74, [Cl] 1.39-10.1, p = 0.009), MACE ([HR] 2.27, [Cl] 1.07-4.81, p = 0.033), and composite endpoint $([\mathrm{HR}] 2.44,[\mathrm{Cl}] 1.31-4.52, \mathrm{p}=$ 0.005). We performed Kaplan-Meier (KM) curves of endpoint events among the three groups (Fig. 2). After controlling for age, gender, marriage, and severity of coronary artery stenosis, comorbidity was found to be an even stronger predictor of MACE ([HR] 2.38) and composite endpoint ([HR] 2. 52).

Table 4

Results for comorbidity as predictors of follow-up events.

\begin{tabular}{|c|c|c|c|c|c|c|c|c|c|c|c|c|}
\hline \multirow[t]{2}{*}{ Event } & \multicolumn{6}{|c|}{ Depression or anxiety vs no psychiatric symptom } & \multicolumn{6}{|c|}{ Comorbidity vs no psychiatric symptom } \\
\hline & $\begin{array}{l}\text { Unadjusted } \\
\text { HR }\end{array}$ & $95 \% \mathrm{Cl}$ & $\mathbf{P}$ & $\begin{array}{l}\text { Adjusted } \\
\text { HR }\end{array}$ & $95 \% \mathrm{Cl}$ & $\mathbf{P}$ & $\begin{array}{l}\text { Unadjusted } \\
\text { HR }\end{array}$ & $95 \% \mathrm{Cl}$ & $\mathbf{P}$ & $\begin{array}{l}\text { Adjusted } \\
\mathrm{HR}\end{array}$ & $95 \% \mathrm{Cl}$ & $\mathbf{P}$ \\
\hline Noncardiac & 2.29 & $\begin{array}{l}0.91- \\
5.78\end{array}$ & 0.078 & 2.11 & $\begin{array}{l}0.82- \\
5.38\end{array}$ & 0.120 & 3.74 & $\begin{array}{l}1.39- \\
10.1\end{array}$ & $0.009 *$ & 2.91 & $\begin{array}{l}1.03- \\
8.18\end{array}$ & $0.043^{*}$ \\
\hline Cardiac & 0.97 & $\begin{array}{l}0.41- \\
2.28\end{array}$ & 0.940 & 1.24 & $\begin{array}{l}0.52- \\
2.97\end{array}$ & 0.623 & 1.25 & $\begin{array}{l}0.45- \\
3.50\end{array}$ & 0.670 & 1.32 & $\begin{array}{l}0.47- \\
3.7\end{array}$ & 0.604 \\
\hline Mace & 1.05 & $\begin{array}{l}0.47- \\
2.34\end{array}$ & 0.899 & 1.19 & $\begin{array}{l}0.63- \\
2.68\end{array}$ & 0.670 & 2.27 & $\begin{array}{l}1.07- \\
4.81\end{array}$ & $0.033^{*}$ & 2.38 & $\begin{array}{l}1.11- \\
5.10\end{array}$ & $0.025^{\star}$ \\
\hline Composite & 1.16 & $\begin{array}{l}0.61- \\
2.21\end{array}$ & 0.643 & 1.22 & $\begin{array}{l}0.64- \\
2.34\end{array}$ & 0.549 & 2.44 & $\begin{array}{l}1.31- \\
4.52\end{array}$ & $0.005^{\star}$ & 2.52 & $\begin{array}{l}1.35- \\
4.69\end{array}$ & $0.004^{*}$ \\
\hline \multicolumn{13}{|l|}{$*: P<0.05$} \\
\hline
\end{tabular}

\section{Discussion}


Following our previous cross-sectional analysis, in this study, we followed-up with the patients for 6 months, 1 year, and over 2 years, and several clinical outcomes were observed. We found that, whether or not multiple factors were adjusted, patients enduring AP with depression symptoms had a significantly high rate of noncardiac readmission and incidence of composite endpoint events while AP patients with anxiety symptoms did not. People with clinical depression and anxiety were found to be at an increased risk of noncardiac readmission and composite endpoint events. Meanwhile, clinical anxiety was found to be associated with MACEs. What we discovered but many other researchers did not keep an eye on was the relationship between the comorbidity of depression and anxiety and prognosis in AP patients, and we elaborated on the fact that this comorbidity might be a predictor of increased risk of noncardiac readmission, MACEs, and composite endpoints.

To our knowledge, this is the first study with an examination of the relationship between depression, anxiety, comorbidity, and noncardiac readmission among AP patients. Current studies underscore the complex relationship between depressive or anxiety symptoms and prognosis in patients with CVD. However, most related studies were focused on populations with myocardial infarction or heart failure, and few medical researchers pay attention to AP. Besides, the endpoint events of many previous studies were normally related to death or reoccurrence of cardiovascular admission instead of noncardiac readmission.

\section{Association of Depression and Prognosis}

In our study, patients with clinical depression symptoms were found to have a 3.41-times higher risk of death and 2.32-times higher risk of noncardiac readmission than those who did not suffer from clinical depression. Pederson et al.[28] showed that depression might be an unrecognised and possibly changeable independent risk factor for unexpected readmission or premature death. Depression is difficult to detect in an acute care environment and is often undertreated. Patients with moderate to severe depression symptoms at discharge with no history of depression may face a twofold increase in the risk of short-term hospital readmission or death. Mitchell et al.[29] reported that the risk of hospital readmission or emergency department treatment within 30 days after discharge among patients with PHQ-9 scores of $\geq 5$ was increased by $73 \%$. Cancino et al.[30] reported a $49 \%$ increase in readmission within 30 days of discharge for patients with mild depression and a $96 \%$ increase for patients with moderate to severe depression. Moraska et al.[31] found that high clinical depression scores on the PHQ-9 were associated with increased risk of hospitalisation (adjusted HR: 1.79, 95\% Cl: 1.30-2.47). In a small study of 144 patients, Kartha et al.[32] found that patients who were diagnosed with severe depression using a standardised scoring algorithm based on PHQ-9 were three times more likely than others to be rehospitalised within 90 days of discharge. We used PHQ-9 scores of $<5,5-9$, and $\geq 10$ as the thresholds for non-depression, mild depression, and moderate to severe depression. We also found that both mild and moderate to severe depression symptoms were associated with noncardiac readmission and composite events.

Previous literature has shown that CHD combined with depression symptoms will lead to an increase in mortality and rehospitalisation, thereby aggravating the severity of the disease, medical expenses, and waste of resources. A cumulative number of studies[33] have shown that comorbidity of mental and physical illnesses would increase the severity of the disease, frequencies of readmissions, and medical expenses. Even the presence of isolated psychiatric symptoms might bring the risk of medical comorbidities[34]. People with psychiatric symptoms, but no psychiatric diagnosis, were prone to more lifelong diseases, healthy problems, and length of hospital stay than those without psychiatric diagnosis or symptoms. Our study has shown that both mild depression and moderate to severe depression could be risk factors for hospital readmission.

\section{Association of Anxiety and Prognosis}

Previous literature has shown that anxiety is a significant risk factor for recurrent CV events or mortality[3, 13, 35-37]. Although we did not analyse death, revascularisation, or nonfatal myocardial infarction independently due to a lack of valid samples, we summed up cardiac readmission, nonfatal stroke, and all the above as MACEs. Tully et al.[38] found that in patients with confirmed CHD, anxiety was a prognostic risk of subsequent MACEs, such as myocardial infarction, left ventricular failure, and stroke. Another study showed that generalised anxiety disorder increased the MACE risk of acute coronary syndrome outpatients by nearly two times within two years[39]. Similar to previous researchers, we identified an association between clinical anxiety and poor CVD prognoses. Although there are few studies in which the authors analysed the relationship between anxiety and noncardiac readmission, we found a positive correlation between clinical anxiety and noncardiac readmission. We did not observe this association in the anxiety symptom group (GAD-7 scale > 5), possibly because the anxiety symptom is transient and usually triggered by a perceived threat, and once the threat diminishes, the anxiety will diminish too. It has been proven that anxiety is prone to poor quality of life of patients with CHD, especially after an acute coronary syndrome event, and that anxious patients have more disabilities and somatic symptoms than others[40-42].

\section{Association of Comorbidity and Prognosis}

The authors of many related studies analysed depression or anxiety as single risk indicators, but we studied them as a comorbid symptom. We discovered that most clinical anxiety patients also have depression symptoms. Denollet and Strik et al.[35, 43] reported that a mixed emotional state consisting of anxiety and depression symptoms, not just depression, was the most common manifestation of patients with myocardial infarction[43]. The author, thus, concluded that anxiety was a common factor of depression after myocardial infarction. A similar symptom overlap was found by Frasure-Smith[39]. Some authors $[44,45]$ found that this connection was produced by the same dysfunctional biology or that depression and anxiety might be derived from parallel genetic dispositions. Furthermore, Scott et al. showed that comorbid depressive-anxiety disorder increased the risk of a series of physical symptoms occurring at the same time[46]. In a follow-up study of women with suspected myocardial ischemia, depression or anxiety could be used to predict CVD events and death more accurately than the independent symptoms[47]. Phillip et al.[48] demonstrated that even after adjustment, the strongest association between CVD and death from all causes appeared in major depressive disorder and generalised anxiety disorder comorbidities. 
Similar to previous researchers, we identified a greater risk of MACEs, noncardiac readmission, and composite events among participants with depression and anxiety.

\section{Limitations}

First, due to the small sample size and prognostic events, some statistical analyses in this study may suffer from overfitting. Second, patients with clinical depression or anxiety were categorised into one group because there were only five patients who had anxiety rather than depression, but this did not affect the analysis of comorbidity and prognosis. Although we did not carry out professional psychiatric interviews to confirm the diagnosis of psychiatric symptoms, we used an easy-to-deploy screening tool that has been fully validated. Moreover, our research was conducted in only one hospital specialised in cardiac care, which ensured the consistency of examination tools, methods, and follow-up times and procedures but limited the generalizability of the findings.

\section{Conclusion}

AP patients with depression symptoms tend to have a higher incidence of noncardiac readmission and composite events than others. Clinical anxiety patients were found to be at increased risk of MACEs. Besides, depression and anxiety seemed to appear simultaneously, and this combination may lead to a worse prognosis than one disorder alone. How clinicians understand this overlap of symptoms will help them determine diagnoses, treatment options, and possible referrals for additional testing and services. In the future, researchers should use effective and reliable measurement methods to further examine the relationship between depression, anxiety, and CHD while paying close attention to the overlapping symptoms.

\section{Abbreviations}

CVD: cardiovascular disease; AP: angina pectoris; MACE: major cardiovascular event; PHQ: patient health questionnaire; GAD: generalised anxiety disorder; HR: hazard ratio; $\mathrm{Cl}$ : confidence interval; CHD: coronary disease; CV: cardiovascular; KM: Kaplan-Meier

\section{Declarations}

\section{Acknowledgments}

Not applicable.

\section{Funding}

None.

\section{Authors' contributions}

BB surveyed the prognostic information. HY collected the baseline data. HW, FL, YL, and AL entered data into the database.BB, HM, and LG did the statistical analyses. BB and HY wrote the first draft. QG, LG, and HM revised the paper. QG, LG were senior physicians principally responsible for the study. All authors read and approved the final manuscript.

\section{Ethics approval and consent to participate}

Ethical approval was given by the medical ethics committee of Guangdong General Hospital with the following reference number: No.GDREC2017203H. All participants gave written informed consent.

\section{Consent for publication}

Not applicable.

\section{Availability of data and materials}

The datasets obtained and/or analysed during the current study are available from the corresponding author on reasonable request.

\section{Competing interests}

The authors declare that they have no competing interests.

\section{Publisher's Note}

Springer Nature remains neutral with regard to jurisdictional claims in published maps and institutional affiliations.

\section{Author information}

${ }^{1}$ Guangdong Cardiovascular Institute, Guangdong Provincial People's Hospital, Guangdong Academy of Medical Sciences, No.106 Zhongshan Er Road, Yuexiu District, Guangzhou 510080, People's Republic of China. 
${ }^{2}$ Guangdong Provincial People's Hospital, Guangdong Academy of Medical Sciences, Guangdong Cardiovascular Institute, No.106 Zhongshan Er Road, Yuexiu District, Guangzhou 510080, People's Republic of China.

${ }^{3}$ School of Medicine, South China University of Technology, Guangzhou, China

${ }^{4}$ Department of Cardiac Rehabilitation, Guangdong Cardiovascular Institute, Guangdong Provincial People's Hospital, Guangdong Academy of Medical Sciences, No.106 Zhongshan Er Road, Yuexiu District, Guangzhou 510080, People's Republic of China.

\section{Provided statement}

This study was a prospective cohort study, following STROBE Statement. All methods were carried out in accordance with relevant guidelines and regulations.

\section{References}

1. Lett HS, Blumenthal JA, Babyak MA, et al. Depression as a risk factor for coronary artery disease: evidence, mechanisms, and treatment. Psychosom Med. 2004. 66(3): 305-15.

2. Denollet J, Schiffer AA, Spek V. A general propensity to psychological distress affects cardiovascular outcomes: evidence from research on the type $D$ (distressed) personality profile. Circ Cardiovasc Qual Outcomes. 2010. 3(5): 546-57.

3. Roest AM, Martens EJ, de Jonge P, Denollet J. Anxiety and risk of incident coronary heart disease: a meta-analysis. J Am Coll Cardiol. 2010. 56(1): $38-46$.

4. Leung YW, Flora DB, Gravely S, Irvine J, Carney RM, Grace SL. The impact of premorbid and postmorbid depression onset on mortality and cardiac morbidity among patients with coronary heart disease: meta-analysis. Psychosom Med. 2012. 74(8): 786-801.

5. Meijer A, Conradi HJ, Bos EH, et al. Adjusted prognostic association of depression following myocardial infarction with mortality and cardiovascular events: individual patient data meta-analysis. Br J Psychiatry. 2013. 203(2): 90-102.

6. Lichtman JH, Froelicher ES, Blumenthal JA, et al. Depression as a risk factor for poor prognosis among patients with acute coronary syndrome: systematic review and recommendations: a scientific statement from the American Heart Association. Circulation. 2014. 129(12): 1350-69.

7. Jha MK, Qamar A, Vaduganathan M, Charney DS, Murrough JW. Screening and Management of Depression in Patients With Cardiovascular Disease: JACC State-of-the-Art Review. J Am Coll Cardiol. 2019. 73(14): 1827-1845.

8. Nicholson A, Kuper H, Hemingway H. Depression as an aetiologic and prognostic factor in coronary heart disease: a meta-analysis of 6362 events among 146538 participants in 54 observational studies. Eur Heart J. 2006. 27(23): 2763-74.

9. Barth J, Schumacher M, Herrmann-Lingen C. Depression as a risk factor for mortality in patients with coronary heart disease: a meta-analysis. Psychosom Med. 2004. 66(6): 802-13.

10. van Melle JP, de Jonge P, Spijkerman TA, et al. Prognostic association of depression following myocardial infarction with mortality and cardiovascular events: a meta-analysis. Psychosom Med. 2004. 66(6): 814-22.

11. Grewal K, Gravely-Witte S, Stewart DE, Grace SL. A simultaneous test of the relationship between identified psychosocial risk factors and recurrent events in coronary artery disease patients. Anxiety Stress Coping. 2011. 24(4): 463-75.

12. Weissman MM, Markowitz JS, Ouellette R, Greenwald S, Kahn JP. Panic disorder and cardiovascular/cerebrovascular problems: results from a community survey. Am J Psychiatry. 1990. 147(11): 1504-8.

13. Grace SL, Abbey SE, Irvine J, Shnek ZM, Stewart DE. Prospective examination of anxiety persistence and its relationship to cardiac symptoms and recurrent cardiac events. Psychother Psychosom. 2004. 73(6): 344-52.

14. Eaker ED, Sullivan LM, Kelly-Hayes M, Sr DRB, Benjamin EJ. Tension and anxiety and the prediction of the 10-year incidence of coronary heart disease, atrial fibrillation, and total mortality: the Framingham Offspring Study. Psychosom Med. 2005. 67(5): 692-6.

15. Kurdyak PA, Gnam WH, Goering P, Chong A, Alter DA. The relationship between depressive symptoms, health service consumption, and prognosis after acute myocardial infarction: a prospective cohort study. BMC Health Serv Res. 2008. 8: 200.

16. May HT, Horne BD, Carlquist JF, Sheng X, Joy E, Catinella AP. Depression after coronary artery disease is associated with heart failure. J Am Coll Cardiol. 2009. 53(16): 1440-7.

17. Kessler RC, DuPont RL, Berglund P, Wittchen HU. Impairment in pure and comorbid generalized anxiety disorder and major depression at 12 months in two national surveys. Am J Psychiatry. 1999. 156(12): 1915-23.

18. Kessler RC, Chiu WT, Demler O, Merikangas KR, Walters EE. Prevalence, severity, and comorbidity of 12-month DSM-IV disorders in the National Comorbidity Survey Replication. Arch Gen Psychiatry. 2005. 62(6): 617-27.

19. Suls J, Bunde J. Anger, anxiety, and depression as risk factors for cardiovascular disease: the problems and implications of overlapping affective dispositions. Psychol Bull. 2005. 131(2): 260-300.

20. Sevincok L, Buyukozturk A, Dereboy F. Serum lipid concentrations in patients with comorbid generalized anxiety disorder and major depressive disorder. Can J Psychiatry. 2001. 46(1): 68-71.

21. Yin H, Liu Y, Ma H, Liu G, Guo L, Geng Q. Associations of mood symptoms with NYHA functional classes in angina pectoris patients: a cross-sectional study. BMC Psychiatry. 2019. 19(1): 85.

Page 8/11 
22. Manea L, Gilbody S, McMillan D. Optimal cut-off score for diagnosing depression with the Patient Health Questionnaire (PHQ-9): a meta-analysis. CMAJ. 2012. 184(3): E191-6.

23. Leavens A, Patten SB, Hudson M, Baron M, Thombs BD, Canadian Scleroderma Research Group. Influence of somatic symptoms on Patient Health Questionnaire-9 depression scores among patients with systemic sclerosis compared to a healthy general population sample. Arthritis Care Res (Hoboken). 2012. 64(8): 1195-201.

24. Spitzer RL, Kroenke K, Williams JB, Löwe B. A brief measure for assessing generalized anxiety disorder: the GAD-7. Arch Intern Med. 2006. 166(10): 1092-7.

25. Swinson RP. The GAD-7 scale was accurate for diagnosing generalised anxiety disorder. Evid Based Med. 2006. 11(6): 184.

26. Zhu Y, Blumenthal JA, Shi C, Jiang R, Patel A, Zhang A, Yu X, Gao R, Wu Y. Sedentary Behavior and the Risk of Depression in Patients With Acute Coronary Syndromes. Am J Cardiol. 2018;121(12):1456-60.

27. Wang L LK, Wang C SL, Hu D DR. Reliability and validity of GAD-2 and GAD-7 for anxiety screening in cardiovascular disease clinic. Sichuan Mental Health. 2014;27((3)):198-201.

28. Pederson JL, Majumdar SR, Forhan M, Johnson JA, McAlister FA, PROACTIVE Investigators. Current depressive symptoms but not history of depression predict hospital readmission or death after discharge from medical wards: a multisite prospective cohort study. Gen Hosp Psychiatry. 2016. 39: 80-5.

29. Mitchell SE, Paasche-Orlow MK, Forsythe SR, et al. Post-discharge hospital utilization among adult medical inpatients with depressive symptoms. J Hosp Med. 2010. 5(7): 378-84.

30. Cancino RS, Culpepper L, Sadikova E, Martin J, Jack BW, Mitchell SE. Dose-response relationship between depressive symptoms and hospital readmission. J Hosp Med. 2014. 9(6): 358-64.

31. Moraska AR, Chamberlain AM, Shah ND, et al. Depression, healthcare utilization, and death in heart failure: a community study. Circ Heart Fail. 2013. 6(3): 387-94.

32. Kartha A, Anthony D, Manasseh CS, et al. Depression is a risk factor for rehospitalization in medical inpatients. Prim Care Companion J Clin Psychiatry. 2007. 9(4): 256-62.

33. Baumeister $\mathrm{H}$, Haschke A, Munzinger M, Hutter N, Tully PJ. Inpatient and outpatient costs in patients with coronary artery disease and mental disorders: a systematic review. Biopsychosoc Med. 2015. 9: 11.

34. Moreno C, Nuevo R, Chatterji S, Verdes E, Arango C, Ayuso-Mateos JL. Psychotic symptoms are associated with physical health problems independently of a mental disorder diagnosis: results from the WHO World Health Survey. World Psychiatry. 2013. $12(3)$ : $251-7$.

35. Strik JJ, Denollet J, Lousberg R, Honig A. Comparing symptoms of depression and anxiety as predictors of cardiac events and increased health care consumption after myocardial infarction. J Am Coll Cardiol. 2003. 42(10): 1801-7.

36. Shibeshi WA, Young-Xu Y, Blatt CM. Anxiety worsens prognosis in patients with coronary artery disease. J Am Coll Cardiol. 2007. 49(20): 2021-7.

37. Moser DK, McKinley S, Riegel B, et al. Relationship of persistent symptoms of anxiety to morbidity and mortality outcomes in patients with coronary heart disease. Psychosom Med. 2011. 73(9): 803-9.

38. Tully PJ, Cosh SM, Baumeister H. The anxious heart in whose mind? A systematic review and meta-regression of factors associated with anxiety disorder diagnosis, treatment and morbidity risk in coronary heart disease. J Psychosom Res. 2014. 77(6): 439-48.

39. Frasure-Smith N, Lespérance F. Depression and anxiety as predictors of 2-year cardiac events in patients with stable coronary artery disease. Arch Gen Psychiatry. 2008. 65(1): 62-71.

40. Lane D, Carroll D, Ring C, Beevers DG, Lip GY. Predictors of attendance at cardiac rehabilitation after myocardial infarction. J Psychosom Res. 2001. 51(3): 497-501.

41. Lane D, Carroll D, Ring C, Beevers DG, Lip GY. Mortality and quality of life 12 months after myocardial infarction: effects of depression and anxiety. Psychosom Med. 2001. 63(2): 221-30.

42. Müller-Tasch T, Frankenstein L, Holzapfel N, et al. Panic disorder in patients with chronic heart failure. J Psychosom Res. 2008. 64(3): $299-303$.

43. Denollet J, Strik JJ, Lousberg R, Honig A. Recognizing increased risk of depressive comorbidity after myocardial infarction: looking for 4 symptoms of anxiety-depression. Psychother Psychosom. 2006. 75(6): 346-52.

44. Agorastos A, Lederbogen F, Otte C. [Treatment of depression in coronary heart disease]. Nervenarzt. 2015. 86(3): 375 - 85; quiz 386-7.

45. Abdelbasset WK, Alqahtani BA. A randomized controlled trial on the impact of moderate-intensity continuous aerobic exercise on the depression status of middle-aged patients with congestive heart failure. Medicine (Baltimore). 2019. 98(17): e15344.

46. Scott KM, Bruffaerts R, Tsang A, et al. Depression-anxiety relationships with chronic physical conditions: results from the World Mental Health Surveys. J Affect Disord. 2007. 103(1-3): 113 - 20.

47. Rutledge T, Linke SE, Krantz DS, et al. Comorbid depression and anxiety symptoms as predictors of cardiovascular events: results from the NHLBIsponsored Women's Ischemia Syndrome Evaluation (WISE) study. Psychosom Med. 2009. 71(9): 958-64.

48. Phillips AC, Batty GD, Gale CR, et al. Generalized anxiety disorder, major depressive disorder, and their comorbidity as predictors of all-cause and cardiovascular mortality: the Vietnam experience study. Psychosom Med. 2009. 71(4): 395-403.

\section{Figures}

Page $9 / 11$ 

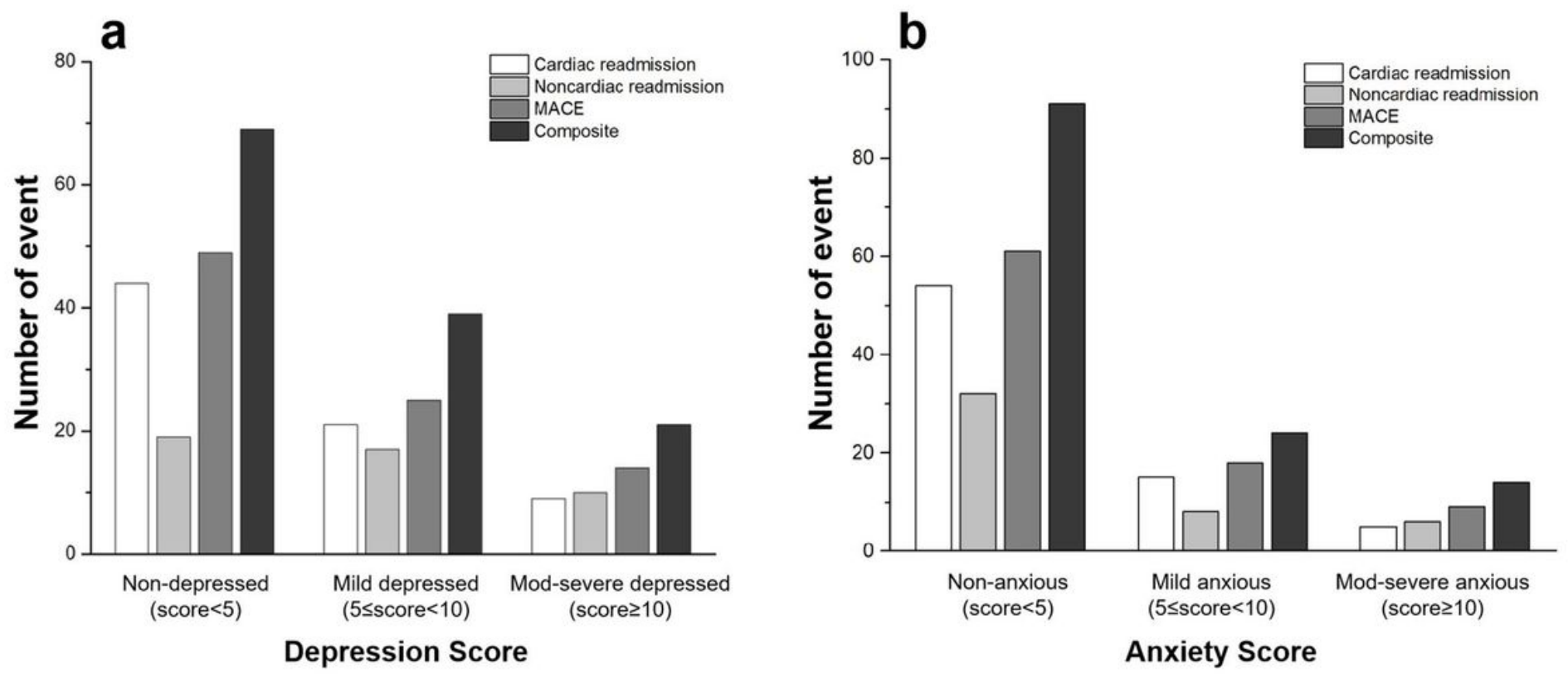

Figure 1

Frequency of events in different psychiatric symptom groups. Figure $1 \mathrm{a}$ is depression group. Figure $1 \mathrm{~b}$ is anxiety group.
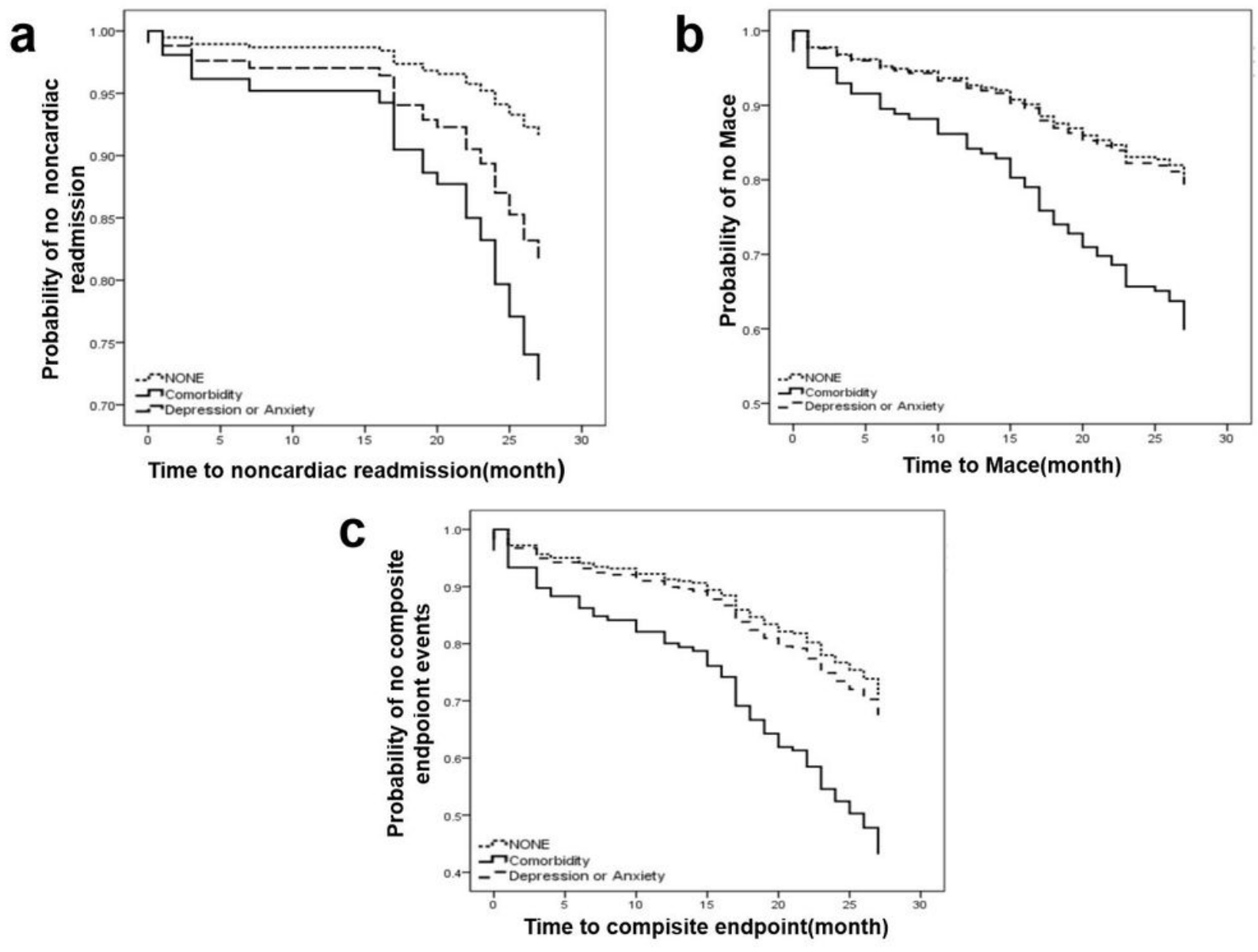

Figure 2

Kaplan Meier curves of follow-up events among no psychiatric symptom group, only depression and anxiety group, and comorbidity group. Figure $2 \mathrm{a}, 2 \mathrm{~b}$, and $2 \mathrm{c}$ is noncardiac readmission, MACEs, and composite endpoint respectively.

\section{Supplementary Files}


This is a list of supplementary files associated with this preprint. Click to download.

- Additionalfile1.docx

- Additionalfile2.docx

- Additionalfile3.doc 